\title{
DISTÚRBIOS DO EQUILÍBRIO HIDROELETROLÍTICO E DO EQUILÍBRIO ACIDOBÁSICO - UMA REVISÃO PRÁTICA
}

\author{
FLUID, ELECTROLYTE AND ACID-BASE DISORDERS. A PRACTICAL REVIEW
}

Paulo Roberto B. Évora'; Celso Luís dos Reis²; Marcus A. Ferez²; Denise A. Conte ${ }^{2}$ \& Luís Vicente Garcia ${ }^{3}$

\begin{abstract}
'Livre Docente em Cirurgia Torácica e Cardiovascular e Coordenador do Laboratório de Função Endotelial da Divisão de Técnica Cirúrgica e Cirurgia Experimental; ${ }^{2}$ Médicos Assistentes do Centro de Tratamento Intensivo (Campus) do Hospital das Clínicas de Ribeirão Preto; ${ }^{3}$ Docente da Disciplina de Dor e Anestesiologia, Diretor do Serviço de Anestesiologia. Departamento de Cirurgia, Ortopedia e Traumatologia da Faculdade de Medicina de Ribeirão Preto da USP.

CorResPondência: Paulo Roberto B. Evora - Rua Rui Barbosa, 367, 7ํAndar - CEP: 14015-120 - Ribeirão Preto, SP
\end{abstract}

EVORA PRB; REIS CL; FEREZ MA; CONTE DA \& GARCIA LV. Distúrbios do equilíbrio hidroeletrolítico e do equilíbrio acidobásico - Uma revisão prática. Medicina, Ribeirão Preto, 32: 451-469, out./dez. 1999.

RESUMO: O equilíbrio hidroeletrolítico e o equilíbrio acidobásico são assuntos de importância para todas as especialidades. Porém, seu entendimento prático é, por vezes, revestido de variados graus de dificuldades.

No presente texto apresenta-se 0 assunto apenas como uma visão prática, adquirida em mais de vinte (20) anos de ensino para estudantes, médicos residentes e médicos pósgraduandos. O texto tem apenas a pretensão didática, sem nenhuma preocupação acadêmica.

UNITERMOS: Água. Eletrólitos. Acidose. Alcalose. Equilíbrio acidobásico. Equilibrio hidroeletrolítico.

Este é um texto de revisão que representa um estilo adotado para o ensino dos equilíbrios hidroeletrolítico (EHE) e acidobásico (EAB) por mais de duas décadas (1975 a 1998). Do ponto de vista acadêmico, a maneira como o assunto é apresentado pode estar sujeita a muitas críticas, mas esta foi a melhor maneira encontrada para ensinar médicos residentes e estudantes. Incluir os dois assuntos em um texto de revisão, sem estendê-lo excessivamente, foi outro desafio. Assim, temos consciência de que a manutenção de uma fluência de estilo pode ter deixado a desejar, uma vez que, em determinados momentos, sempre com a preocupação da extensão do texto, ele se torna mais próximo do estilo que se lê em manuais.

Os principais objetivos relativos ao EHE, a serem atingidos pelo leitor, podem ser enumerados como a seguir:

1. Reconhecer os compartimentos hídricos e a água total do organismo.
2. Reconhecer os efeitos da permeabilidade e tonicidade nas diferenças de composição entre os líquidos intracelular e extracelular.

3. Ter noções de equilíbrio hídrico.

4. Reconhecer a importância das chamadas perdas para o terceiro espaço.

5. Reconhecer e tratar os principais distúrbios do equilíbrio hídrico (desidratação, edema e intoxicação hídrica).

6. Reconhecer e tratar os principais distúrbios do equilíbrio eletrolítico (hipo e hipernatremia, hipo e hiperpotassemia, hipo e hipercalcemia, hipo e hipermagnesemia).

Os principais objetivos relativos ao EAB, a serem atingidos pelo leitor, podem ser enumerados como a seguir:

1. Reconhecer os dois mecanismos básicos que os sistemas orgânicos utilizam para a manutenção do 
EAB: cota fixa de ácidos da dieta e destino do $\mathrm{CO} 2$ gerado como produto final do metabolismo.

2. Deduzir a Equação de Henderson-Hasselbalch (Tampão bicarbonato, componente metabólico ou não respiratório/função renal; componente respiratório/função pulmonar).

3. Conhecer os mecanismos de excreção do $\mathrm{H}^{+}$.

4. Reconhecer as evidências de que o organismo animal possui mecanismos naturais de defesa contra a acidose mais eficientes do que os mecanismos de defesa contra a alcalose.

5. Conhecer os principais sistemas tampões além do tampão bicarbonato.

6. Conceituar "Base-Excess" e Reserva Alcalina.

7. Entender as interrelações entre o EAB e EHE através do conceito do "Anion Gap".

8. Saber interpretar uma gasometria, diagnosticando os desvios do EAB.

9. Reconhecer os fatores que podem influenciar os resultados de uma gasometria.

10. Conhecer as causas mais comuns dos desvios do EAB: alcalose respiratória, acidose respiratória, Síndrome da Angústia Respiratória do Adulto (SARA), acidose metabólica e alcalose metabólica.

11. Saber tratar os distúrbios do EAB.

12. Conhecer os efeitos deletérios da acidose aguda.

13. Conhecer os efeitos deletérios da alcalose aguda.

\section{EQUILÍBRIO HIDROELETROLÍTICO E SEUS DESVIOS}

\subsection{COMPARTIMENTOS HÍDRICOS E TONICIDADE}

\subsection{1 Água total do organismo}

Embora a concentração dos íons de uma solução seja rapidamente determinada laboratorialmente, é bom ressaltar que os volumes dos vários compartimentos hídricos têm uma importância ainda maior no tratamento cirúrgico. Embora a extensão e as distorções presentes nestes volumes hídricos não sejam prontamente determinadas por medida direta, é essencial um conhecimento das várias subdivisões da água total do organismo para compreender e tratar os problemas hidroeletrolíticos mais complexos.

A água tritiada foi utilizada como isótopo para determinar a água do organismo. A água representa 50 a $60 \%$ do peso corporal, estando presente, em maior quantidade, nas pessoas magras, e, em menor quantidade, nas obesas. As mulheres têm uma percentagem menor de água total no organismo devido à maior quantidade de tecido adiposo subcutâneo. A água do organismo pode ser dividida em compartimentos:

a) Intracelular - $40 \%$ do peso corpóreo,

b) Extracelular - 20\% do peso corpóreo (Intersticial $5 \%$ e Intravascular $15 \%$ ).

O líquido intersticial não pode ser medido diretamente por isótopos usados nas dosagens de diluição do indicador, porém consiste na diferença entre o líquido extracelular total e o volume localizado no espaço intravascular.

Os três compartimentos que compõem a água total do organismo também diferem em composição. O potássio $\left(\mathrm{K}^{+}\right)$, o cálcio $\left(\mathrm{Ca}^{2+}\right)$ e o magnésio $\left(\mathrm{Mg}^{2+}\right)$ representam os principais cátions na água intracelular, e os fosfatos e as proteínas, os principais ânions. Grande parte do sódio $\left(\mathrm{Na}^{+}\right)$é eliminada desse compartimento por processos que requerem energia (Bomba $\mathrm{Na}^{+}-\mathrm{K}^{+}$ou $\mathrm{Na}^{+}-\mathrm{K}^{+}$ATPase). Por outro lado, o sódio é o principal cátion do líquido extracelular (LEC), enquanto o $\mathrm{Cl}^{-}$e o $\mathrm{HCO}^{-}$representam os principais ânions. A importância do $\mathrm{Na}^{+}$está relacionada com o controle que ele exerce na distribuição da água em todo o organismo. O número de moléculas de $\mathrm{Na}^{+}$por unidade de água determina a osmolalidade do LEC. $\mathrm{Se}$ o $\mathrm{Na}^{+}$é perdido, a água é excretada na tentativa de manter a osmolalidade normal, e se o $\mathrm{Na}^{+}$é retido, a água também deve ser retida para diluí-lo. A quantidade total de $\mathrm{Na}^{+}$existente no organismo é de aproximadamente $4000 \mathrm{mEq}$, porém, a maior parte dessa quantidade encontra-se no esqueleto.

Para fins didáticos, as composições iônicas do plasma e do líquido intersticial podem ser consideradas idênticas, embora possa haver pequenas diferenças, resultantes da concentração desigual de proteína. O plasma tem um conteúdo muito maior de proteína, e esses ânions orgânicos exigem um aumento na concentração total de cátions. A concentração dos ânions inorgânicos é algo menor no plasma do que no interstício. Essas relações são estabelecidas pelo equilíbrio de Gibbs-Donnan.

\subsubsection{Permeabilidade e tonicidade}

As diferenças na composição entre o líquido intracelular (LIC) e o LEC são mantidas ativamente pela membrana celular. Essa é uma membrana semipermeável, uma vez que é totalmente permeável à água, porém é seletivamente permeável a outras substâncias. Embora o número total de osmoles seja igual em ambos os lados da membrana celular, a pressão osmótica efetiva é determinada por substâncias 
que não podem passar através da membrana semipermeável. Isso é bem estabelecido no limite da célula capilar, entre o plasma e o líquido intersticial. A passagem limitada das proteínas plasmáticas é responsável pela pressão osmótica eficaz, geralmente, conhecida como pressão coloidosmótica desse compartimento. Analogamente, as substâncias cuja passagem é limitada pela membrana celular, tais como o sódio, contribuem para a pressão osmótica eficaz do LEC. É importante ter em mente que a água atravessa livremente todas as membranas celulares. Isso significa que o movimento da água através da membrana celular equalizará sempre a pressão osmótica eficaz no interior e no exterior da célula. Se houver alteração da pressão osmótica eficaz no LEC, haverá uma redistribuição de água entre os compartimentos. Esses desvios da água orgânica resultam de alterações na composição, e não alterações no volume, de maneira que a água intracelular é muito menos afetada pelos aumentos ou diminuições do LEC do que pela pressão osmótica.

A pressão osmótica de uma solução é referida em termos de osmoles ou miliosmoles, e está relacionada com o número de partículas osmoticamente ativas, presentes na solução. Portanto, $1 \mathrm{mMol}$ de $\mathrm{NaCl}$, que se dissocia em $\mathrm{Na}^{+}$e $\mathrm{Cl}^{-}$, contribui com dois miliosmoles. Assim, $1 \mathrm{mMol}$ de uma substância não ionizada, tal como a glicose ou a uréia, contribuirá com um mOsm. Quando se consideram os problemas hidroeletrolíticos, os termos tais como osmol ou miliosmol não são tão freqüentemente empregados como o são o equivalente e o milequivalente. O equivalente de um íon é o seu peso atômico, expresso em gramas, dividido pela sua valência. Quando se trata de íons univalentes, $1 \mathrm{mEq}$ é igual a $1 \mathrm{mMol}$. No caso dos íons divalentes, (um) mMol é igual a dois mEq. Esses conceitos são importantes para o entendimento do equilíbrio eletrolítico corpóreo, uma vez que, em qualquer solução, o número total de cátions expressos em $\mathrm{mEq}$ deve ser igual ao número de ânions, também expressos em mEq.

\subsubsection{Balanço hídrico}

O peso corporal tornou-se uma medida bastante importante, porque as alterações agudas refletem aumentos ou diminuições na água total do organismo. Como foi observado anteriormente, a água total do organismo representa 50 a $60 \%$ do peso corporal. Em um adulto de 70 quilos essa fração seria de 35 a 42 litros de água, uma ampla faixa que está relacionada com a idade, o sexo e as diferenças na composi- ção do organismo existentes entre adultos normais. Assim, uma única medida do peso corporal, geralmente, tem pouco valor no cálculo da água total. No entanto, no contexto da unidade de tratamento intensivo, as mudanças do peso a curto prazo devem-se, em grande parte, mais às alterações na água total do organismo, mesmo se o valor absoluto da água total permanecer incerto; o conhecimento da direção e da intensidade da alteração desse parâmetro pode revestir-se de grande importância no diagnóstico e tratamento de distúrbios complexos do EHE. Quando não se dispõe de camas-balanças, ou quando não se podem fazer pesagens fiéis devido à condição do paciente, tornase necessário fazer determinações do balanço hídrico (BH). O BH diário, incluindo uma estimativa das perdas por evaporação, pode ser acrescentado ou subtraído, sendo que o BH cumulativo resultante, reflete as alterações da água total do organismo.

$\mathrm{O}$ BH teve aplicação clínica limitada devido às dificuldades em se medir o conteúdo hídrico dos alimentos sólidos e das fezes, a água e as perdas pela evaporação. Na verdade, alguns desses problemas são simplificados no pós-operatório (PO), uma vez que quase todo o aporte de água é intravenoso, sendo facilmente medido. Devido à ausência de ingestão por via oral, as fezes não são frequientes e o débito urinário pode ser medido com facilidade. As perdas por evaporação são inferiores a $1000 \mathrm{ml} /$ dia nos pacientes afebris e ainda menores, quando se umidificam as vias aéreas com vapor aquecido, e nos pacientes febris existem cálculos que possibilitam avaliar as perdas aproximadas. No ambiente com ar condicionado, muitos pacientes febris ainda perderão menos que dois litros por dia através da pele e da respiração. A hiperventilação dos pacientes com febre elevada pode eliminar até três litros de água por dia, porém isso é incomum. As queimaduras graves são uma exceção óbvia, porém, à exceção desse grupo de pacientes, podem ser feitas aproximações razoáveis da perda evaporativa de água que, por sua vez, possibilita o cálculo do BH diário e cumulativo, a partir da ingesta de líquidos e de registros de débito.

Uma vez que as pesagens seriadas ou o BH geram informações principalmente sobre as alterações na água total do organismo, outros meios são importantes para diagnosticar um decréscimo ou um excesso no volume absoluto. O volume plasmático é a única medida de volume clinicamente disponível, porém pode ter um valor limitado, uma vez que os valores normais previstos variam consideravelmente. $\mathrm{O}$ 
exame clínico do paciente é essencial, e certos sinais e sintomas indicam a existência de anormalidade no volume hídrico do organismo.

O sistema cardiovascular é o indicador mais sensível, e uma Pressão Venosa Central (PVC) abaixo de $3 \mathrm{cmH}_{2} 0$, taquicardia e até mesmo hipotensão indicam um déficit de volume. Na Unidade de Terapia Intensiva (UTI) o excesso de volume é mais comum, uma vez que os pacientes recebem, durante a ressuscitação, grandes volumes de líquido por via endovenosa. São sinais bem reconhecidos de sobrecarga hídrica: a PVC aumentada, o Débito Cardíaco (DC) elevado, ritmo de galope cardíaco, uma segunda bulha pulmonar hiperfonética, a congestão pulmonar e algumas vezes o edema.

O Sistema Nervoso Central (SNC) pode fornecer evidências de déficit na água total do organismo, tais como apatia, reflexos tendinosos, profundos e diminuídos, estupor ou coma. Porém, os excessos isotônicos exercem pouco ou nenhum efeito na função do SNC.

Os sinais teciduais são tradicionalmente usados para avaliar a hidratação, porém podem aparecer lentamente. O turgor cutâneo diminuído, os olhos encovados e a língua seca são sinais tardios de déficit de líquido, assim como o edema subcutâneo é um sinal tardio de sobrecarga.

Finalmente, deve-se salientar que o conhecimento da composição das várias secreções orgânicas pode ser de grande valia para um raciocínio mais dirigido diante de alterações do EHE. Essas composições podem ser obtidas em tabelas próprias, ou pela análise bioquímica de alíquotas dessas secreções.

\subsubsection{A importância das perdas para o tercei- ro espaço}

É possível ocorrer uma desidratação por seqüestro interno de líquido. Como já se descreveu, os compartimentos normais são o LEC (IV + INT) e o LIC. Quando ocorrem lesões, como as queimaduras, trauma acidental e cirurgia, o LEC é seqüestrado na área de lesão, formando um "terceiro" espaço líquido anormal. Esta perda se faz a expensas do LEC normal e reduz o seu volume efetivo, produzindo hemoconcentração e hipovolemia. A terapêutica imediata com soluções salinas ou balanceadas em sais e plasma, restaura os volumes plasmático e do interstício. As perdas para o terceiro espaço devem ser repostas como uma perda externa, uma vez que o líquido seqüestrado não tem nenhum valor do ponto de vista volêmico do paciente. À medida que este espaço di- minui ("resolução do terceiro espaço"), após a estabilização do paciente, ocorre uma auto-infusão de líquido que, se não for eliminada por uma função renal adequada, pode transformar-se em edema intersticial com conseqüiente quadro de SARA. Este problema tem grande importância na mortalidade de pacientes traumatizados após 48 a 72 horas de estabilizado o quadro inicial de choque hipovolêmico. Se o paciente não apresentar boa diurese, deve-se restringir líquidos, usar diuréticos e até processos dialíticos.

\subsection{DISTÚRBIOS DO EQUILÍBRIO HÍDRICO}

\subsubsection{Desidratação}

\section{a) Definição}

A desidratação é uma diminuição na quantidade total de água corpórea com hiper, iso ou hipotonicidade dos fluidos orgânicos.Os testes de laboratório mostram $\mathrm{Hb}$ e $\mathrm{Ht}$, uréia, creatinina, proteínas e densidade específica da urina elevados, e sódio urinário baixo (a não ser que haja doença renal primária).

\section{b) Etiologia}

Perdas gastrintestinais (diarréia, vômitos, aspiração gástrica); perdas geniturinárias (poliúria de qualquer etiologia, doença de Addison, diabetes, terapêutica com diuréticos, etc.); perdas pela pele (sudorese abundante, queimaduras, etc.); ingestão insuficiente (numerosas etiologias).

\section{c) Sinais e Sintomas}

Sede (com perda de 2\% do peso corpóreo); precoces (mucosas secas, pele intertriginosa seca, perda da elasticidade da pele, oligúria); tardios (taquicardia, hipotensão postural, pulso fraco, obnubilação, febre, coma); morte (com perda de $15 \%$ do peso corpóreo)

\section{d) Conduta}

1) corrigir o problema primário; 2) a diferença entre o peso prévio ao processo mórbido e o peso atual (na possibilidade de obtenção), corresponde ao grau de desidratação e o volume a ser reposto; 3 ) se não for possível a utilização do peso como parâmetro, estimar o grau de desidratação, combinando a história com os sinais e sintomas e exames de laboratório; classifica-se, deste modo, a desidratação em: Leve (perda de 3\% do peso corpóreo); Moderada (perda de 5 a 8\%) e; Grave (perda de 10\%); 4) reponha o volume perdido, representado pela perda do peso corpóreo, dando $1 / 2$ do volume total a repor nas primeiras doze horas, dependendo do estado clínico; 5) determine o estado iônico do paciente e reponha sal de acordo com 
as necessidades, utilizando soluções eletrolíticas adequadas; 6) quando houver desidratação grave, use soluções eletrolíticas em grandes quantidades, não espere pelos resultados das determinações eletrolíticas.

\subsubsection{Edema}

O edema não é, por si só, uma emergência. A sua presença, no entanto, é indicativa de doença de base, cuja natureza deve ser elucidada. As causas cardíacas, hepáticas ou renal são as mais comuns. Não se deve dar diuréticos até que se tenham analisados os múltiplos fatores que podem levar ao edema. Os diuréticos empregados sem critério podem induzir distúrbios eletrolíticos, coma hepático, azotemia e arritmias.

\subsubsection{Intoxicação hídrica}

\section{a) Definição}

É o oposto direto da hipertonicidade (por sobrecarga de solutos), causada pela excessiva ingestão de água na presença de baixa diurese.

A fonte de água pode ser a ingestão oral, mas, mais freqüentemente, é uma má orientação e excessiva terapêutica parenteral com glicose e água. As irrigações dos colos, particularmente as destinadas a reduzir a distensão pós-operatória, podem resultar em retenção substâncial de volumes de água.

Os pacientes com enfermidades crônicas, debilitantes, com câncer, insuficiência cardíaca congestiva ou enfermidade hepática ou renal, são propensos a ter um LEC expandido e algum grau de hipotonicidade antes de vir à cirurgia ou de sofrer um trauma acidental. Esses pacientes estão particularmente sujeitos a reter excesso de água no pós-operatório e a expandir, e, posteriormente, diluir o LEC.

\section{b) Quadro clínico}

As náuseas, a astenia e uma queda do volume urinário são os sintomas mais precoces, seguidos por convulsão e coma. Sempre ocorrerá rápido aumento de peso, podendo observar-se edema periférico e pulmonar. Os achados laboratoriais incluirão rápida queda na concentração do $\mathrm{Na}^{+}$sérico e na osmolalidade plasmática. A urina pode conter substanciais quantidades de sódio que, em presença de uma baixa concentração plasmática, indicam uma inapropriada excreção de sódio, devido ao excesso de volume do LEC, se estiverem afastadas doença renal e insuficiência adrenal.

A velocidade de queda do sódio plasmático parece ser de maior importância do que seu valor absoluto. O edema cerebral é a causa do coma e das convulsões, sendo encontrados, comumente, valores de $\mathrm{Na}^{+}$inferiores a $120 \mathrm{mEq} / \mathrm{l}$.

\section{c) Conduta}

Restrição hídrica, reposição de sódio (administração de sal hipertônico em pequenas quantidades - $300 \mathrm{ml}$ de NaCL a 3\%), uso cuidadoso de diurético osmótico (manitol) e administração lenta de glicose hipertônica. Nenhuma tentativa deverá ser feita para uma "reposição calculada do déficit de sódio", baseada no volume do LEC e na unidade de déficit de sódio, porque resultará numa grave sobrecarga. $\mathrm{O}$ tempo com a perda insensível de água pelos pulmões, juntamente com o fluxo de urina, pode, por si só, levar o paciente gradualmente ao normal.

\subsection{DISTÚRBIOS DO EQUILÍBRIO ELETROLÍTICO}

\subsubsection{Alterações do sódio}

O sódio é o cátion que existe em maior quantidade nos líquidos extracelulares. Os íons de sódio participam da manutenção do $\mathrm{EH}$, da transmissão dos impulsos nervosos e da contração muscular. A sua concentração normal no LEC varia entre 136 e $144 \mathrm{mEq} / \mathrm{l}$. O EHE é regido por um princípio fisiológico importante: a água vai para onde for o sódio. Quando os rins retêm sódio, a água também é retida. Por outro lado, e a sua excreção é acompanhada pela excreção de água. Este é o princípio da maioria dos diuréticos. Quando a ingestão de sódio diminui, ou quando o paciente perde líquidos, o organismo procura reter sódio por ação da aldosterona nos túbulos renais, onde promove a reabsorção do sódio.

\subsubsection{Hiponatremia}

Pode ser resultado da deficiência corpórea do sódio, uma diluição por excesso de água, ou uma combinação dos dois fatores. A causa mais comum é a excreção ineficiente de água frente ao excesso de administração (freqüentemente induzida iatrogênicamente)

Etiologia - é importante tentar diferenciar o tipo de hiponatremia presente, isto é, super-hidratação ou deficiência de sódio, já que a causa básica e o tratamento são muito diferentes.

A depleção de sódio (hiponatremia) é encontrada quando as perdas de fluidos que contêm $\mathrm{Na}^{+}$ com continuada ingestão de água: perdas gastrintestinais (diarréia, vômito); perdas pela pele (lesões exsudativas da pele, queimaduras, sudorese); seqüiestros no corpo (obstrução intestinal); perda renal (primária ou secundária a estados de depleção, incluindo as perdas por diuréticos e na doença de Addison). 
A hiponatremia dilucional pode ocorrer na: Insuficiência Cardíaca Congestiva (ICC), cirrose, doença renal com oligúria, síndrome de secreção inadequada do Hormônio Anti-Diurético (HAD), doença de Addison.

Outras causas incluem: síndrome de hiponatremia familiar (assintomática, vista em muitos tipos de doenças de depleção); sódio sérico artificial baixo, como nas hiperlipidemias, hiperglicemias e hiperproteinemia do mieloma múltiplo.

Sinais e sintomas - dificuldade na concentração mental, alterações da personalidade, confusão, delírio, coma, oligúria.

Conduta - tratar a doença de base, pesar o paciente, determinar se a hiponatremia é secundária à perda de sal ou à sobrecarga de água.

Nos casos de hiponatremia por depleção salina, repor o sódio, calculando o seu déficit com base no volume da água total (60\% do peso para os homens e $50 \%$ do peso para as mulheres). A prática revela que a reposição à base apenas do LEC ( $20 \%$ do peso corpóreo) retarda a resolução do problema.

A hiponatremia por excesso de água é tratada como intoxicação hídrica: repor sódio só em caso com menos de $110 \mathrm{mEq} / \mathrm{l}$, manitol (observar cuidadosamente sinais de ICC).

A síndrome de hiponatremia familiar e sódio baixo artificial não necessita, em geral, de tratamento.

\subsubsection{Hipernatremia}

Está, geralmente, associada à desidratação com $\mathrm{Na}^{+}$superior a $150 \mathrm{mEq} / \mathrm{l}$.

Etiologia - perda de água superior à de sódio: diarreia e vômitos, insuficiência renal, diabetes insipidus, diabetes mellitus, febre, insolação, hiperventilação; reposição insuficiente das perdas hídricas: diminuição da ingestão hídrica por náuseas, vômitos ou incapacidade física; administração de sobrecarga de soluto: suplementação de proteínas e sal, na alimentação, por sonda, envenenamento acidental por sal de cozinha, diuréticos osmóticos, diálise; excesso de esteróides.

Sinais e Sintomas - a detecção clínica precoce pode ser difícil, porque o plasma hipertônico atrai água das células, escondendo os sinais de colapso circulatório, vistos na desidratação hiponatrêmica. $\mathrm{O}$ turgor cutâneo pode ser normal (em oposição à desidratação hiponatrêmi- ca). As mucosas e a boca estão secas. A sede está presente, mas pode ser ocultada pela náusea e vômitos. A fraqueza muscular e as cãibras são comuns. Pode ocorrer febre (maior que $40^{\circ} \mathrm{C}$ graus em alguns casos). Sinais e sintomas neurológicos, incluindo tremor, hiperreflexia profunda, memória alterada, confusão e alucinações podem estar presentes.

Conduta - pesar o paciente e tratar a doença primária. Estimar a porcentagem de perdas em termos de peso corpóreo, planejar a reposição de aproximadamente metade do volume nas primeiras oito a doze horas. O edema cerebral pode complicar a reposição muito rápida.

Nota: uma estimativa grosseira da osmolalidade sérica pode ser obtida pela seguinte fórmula:

$$
\text { Osmolalidade }=2\left(\mathrm{Na}^{+}+\mathrm{K}^{+}\right)+\underset{5.6}{\text { Uréia }}+\frac{\text { Glicemia }}{18}
$$

\subsubsection{Alterações do potássio}

O potássio é o principal cátion intracelular que regula a excitabilidade neuromuscular e a contratilidade muscular. O potássio é necessário para a formação do glicogênio, para a síntese protéica e para a correção do desequilíbrio acidobásico. A sua importância no EAB é importante, porque os íons $\mathrm{K}^{+}$competem com os íons $\mathrm{H}^{+}$. Por conseguinte, na acidose, ocorre eliminação de um $\mathrm{H}^{+}$para cada $\mathrm{K}^{+}$retido. $\mathrm{Na}$ alcalose, dá-se o contrário. A regulagem do potássio está a cargo, principalmente, dos rins. Quando a aldosterona aumenta, a urina elimina maior quantidade de potássio e o nível de potássio no sangue pode diminuir. Outro mecanismo regulador baseia-se na permuta com o $\mathrm{Na}^{+}$nos túbulos renais. A retenção de sódio é acompanhada pela eliminação de potássio.

\begin{tabular}{|rcr|}
\hline Tabela I - Diagnóstico diferencial de hiponatremia & \\
\hline & $\begin{array}{c}\text { Depleção de sódio } \\
\text { (Hiponatremia real) }\end{array}$ & $\begin{array}{c}\text { Excesso de água } \\
\text { (Hiponatremia dilucional) }\end{array}$ \\
\hline $\begin{array}{r}\text { Uréia } \\
\text { Hematócrito }\end{array}$ & elevada & normal \\
Pressão Arterial & geralmente baixa & normal ou baixo \\
Pulso & rápido & normal \\
Pele & fria, pastosa & normal \\
Mucosas & secas & normal, úmida \\
Turgor cutâneo & diminuído & úmidas \\
Edema & ausente & normal \\
Urina & pouca, concentrada & normal ou poliúrica, diluída \\
\hline & & vezes, presente \\
\hline
\end{tabular}


Os níveis séricos normais de potássio oscilam entre 3,5 a $5 \mathrm{mEq} / \mathrm{l}$. Ressalte-se que os valores plasmáticos representam os valores extracelulares. Sua normalidade ou o seu aumento não significam alterações globais dos seus valores, isto porque ele predomina no LIC. Já o seu valor plasmático é importante no caso de hiperpotassemia, porque é o aumento dos seus níveis extracelulares que pode levar à parada cardíaca diastólica.

\subsubsection{Hiperpotassemia}

Etiologia - insuficiência renal aguda, doença de Addison, acidose, transfusões e hemólise, lesões por esmagamento de membros e outras causas de degradação de proteínas, grande ingestão de $\mathrm{K}^{+}$frente à insuficiência renal, entre outras.

Sinais e Sintomas - fraqueza muscular, paralisia flácida, diminuição de ruídos hidroaéreos, parestesias (face, língua, pés, mãos), irritabilidade muscular, arritmias cardíacas e outras alterações do Eletrocardiograma (ECG) (onda T "em campânula", complexos QRS alargados), parada cardíaca em diástole.

Conduta - gluconato ou cloreto de cálcio, bicarbonato de sódio, solução polarizante sem K (glicose-insulina), resinas de troca iônica (Kayexalate, Sorcal), diálise.

\subsubsection{Hipopotassemia}

Etiologia - perdas gastrintestinais (diarréia, fístula Gastrintestinal (GI), vômitos); perdas geniturinárias (acidose tubular renal e outras doenças renais, doença de Cushing, síndrome de Cohn, uso de diuréticos); ingestão insuficiente (notar que há perda obrigatória nas fezes); desvio iônico (alcalose).

Sinais e Sintomas - neuromusculares (fraqueza muscular, parestesias); renais (concentração prejudicada, poliúria); gastrintestinais (náuseas, íleo adinâmico); SNC (irritabilidade, letargia, coma); cardíacos (arritmias tipo bigeminismo e/ou trigeminismo, onda $\mathrm{U}$ ao ECG)

Conduta - via oral ( $\mathrm{KCl}$ xarope, $\mathrm{K}$ efervescente ou em comprimidos); via endovenosa (aumentando-se a concentração de $\mathrm{K}^{+}$nas soluções eletrolíticas usuais, solução polarizante: G-I-K).

Nota: a reposição do $\mathrm{K}^{+}$se faz de maneira empírica, sendo um esquema usual a reposição de 40 a $60 \mathrm{mEq} / \mathrm{L}$ por via EV (Endovenosa) a velocidades não maiores do que $30-40 \mathrm{mEq} / \mathrm{hora}$.

Casos especiais - os cirróticos são especialmente suscetíveis às complicações da hipopotassemia e devem ser tratados agressivamente com rela- ção a tal problema. Os pacientes digitalizados são especialmente suscetíveis às arritmias, se hipopotassêmicos, e também necessitam de tratamento intensivo para esta alteração eletrolítica. Deve-se prevenir a hipopotassemia após tratamento para acidose em geral, e da acidose diabética, em especial.

\subsubsection{Alterações do cálcio}

O cálcio ocupa o quinto lugar entre os elementos mais abundantes no corpo humano. $\mathrm{O}$ organismo precisa do cálcio para a integridade e estrutura das membranas celulares, condução adequada dos estímulos cardíacos, coagulação sangüínea e formação e crescimento ósseos. O cálcio se encontra nos líquidos orgânicos sob três formas diferentes: 10 cálcio ionizado (4,5 mg/100ml); 20 cálcio não difusível, formando complexos com ânions protéicos $(5 \mathrm{mg} / 100 \mathrm{ml})$ e; 3) sais de cálcio, tais como citrato e fosfato de cálcio (q mg/100ml). Alguns laboratórios clínicos indicam os níveis de cálcio em $\mathrm{mEq} / \mathrm{l}$. O cálcio contido nos líquidos orgânicos representa uma pequena porcentagem do cálcio total, sendo que a maior parte dele se encontra nos ossos e dentes.

O cálcio contido no LEC é regulado pela ação dos hormônios das paratireóides e tireóides. O hormônio da paratireóide regula o equilíbrio entre o cálcio contido nos ossos, a absorção de cálcio pelo trato gastrintestinal e a eliminação do cálcio pelos rins. A tireocalcitonina, produzida pela tireóide, também desempenha um certo papel na determinação dos níveis séricos do cálcio, porque inibe a reabsorção do cálcio dos ossos.

\subsubsection{Hipocalcemia}

Etiologia - perda de tecido da paratireóide após tireoidectomia, hipoparatireoidismo idiopático, insuficiência renal (raramente sintomática).

Sinais e Sintomas - parestesias (especialmente perorais e nas mãos e pés); labilidade emocional; miastenia e cãibras; diarréia e poliúria; disfagia; estridor laríngeo e broncoespasmo, convulsões; arritmias cardíacas e intervalo Q-T aumentado; espasmo carpopedal (espontâneo ou com uso de manguito de pressão durante três minutos, inflado acima da pressão sistólica - Sinal de Trousseau); contração do músculo facial após leve golpe na frente da orelha - Sinal de Chvostek; opistótono.

Conduta - a reposição é empírica, usando-se tantas ampolas de gluconato de cálcio quantas forem necessárias, até o desaparecimento dos sinais clínicos. A infusão venosa deve ser lenta. Nos casos de 
hipoparatireoidismo, pode-se utilizar extrato de paratireóide (100 a 200 unidades USP) por via EV. No tratamento pós-controle da fase aguda, deve-se acrescentar cálcio oral e Vitamina D.

Nota importante: se não houver resposta ao tratamento com cálcio, considerar a possibilidade de hipomagnesemia.

\subsubsection{Hipercalcemia}

Etiologia - hiperparatireoidismo, neoplasias (carcinoma, leucemia, linfoma, mieloma múltiplo), sarcoidose, intoxicação por Vitamina $\mathrm{D}$, hipo e hipertireoidismo, síndrome do "milk-alkali", insuficiência adrenal.

Sinais e Sintomas - fraqueza, anorexia e vômitos, constipação, sonolência, estupor, coma, cefaléia occipital, intervalo Q-T e segmento ST supranivelados no ECG, arritmias.

Conduta - o objetivo final do tratamento deve ser dirigido para eliminar a causa, se possível. O tratamento de urgência das crises hipercalcêmicas inclui: hidratação com Soro Fisiológico (SF) e diurese forçada com diuréticos (pode ser suficiente nos casos leves).

O sulfato de sódio ( $0,12 \mathrm{M})$ um (1) litro em 4-6 horas, seguido de uma infusão adicional de três litros em vinte e quatro (24) horas. O sulfato de sódio é mais eficiente que o SF, porém podem ocorrer hipernatremia, hipopotassemia e hipomagnesemia, apesar de sua ação ser de curta duração.

Outra opção para o tratamento da hipercalcemia grave são os fosfatos $\left(\mathrm{K}_{2} \mathrm{HPO}_{4}-1,5 \mathrm{~g}\right.$ em infusão $\mathrm{EV}$, correndo durante 7 horas). Os fosfatos podem causar efeitos cardíacos letais, sendo a sua administração Via Oral (VO) mais segura. Além disso os fosfatos podem causar insuficiência renal por depósito de cálcio no rim. São especialmente perigosos nos pacientes com uremia.

Os glicocorticóides podem ser úteis nos casos de metástases ósseas, porém não são efetivos nos casos de hipercalcemia causada pelo excesso do hormônio da paratireóide.

\subsubsection{Alterações do magnésio}

O magnésio ocupa o segundo lugar, por ordem de importâncias, entre os cátions do LIC. Ele é indispensável para as atividades enzimáticas e neuroquímicas, assim como para a excitabilidade dos músculos. Seus níveis plasmáticos variam entre 1,5 e $2,5 \mathrm{mEq} / 1$.
A regulagem dos níveis de magnésio é indireta, estando a cargo da eliminação renal, além de depender do hormônio das paratireóides. As alterações dos níveis de magnésio são, freqüentemente, associadas a doenças graves e manifestam-se por sinais sugestivos de alterações das funções neuromusculares.

\subsubsection{Hipermagnesemia}

Etiologia - o excesso de magnésio é quase sempre o resultado de uma insuficiência renal e inabilidade em excretar o que foi absorvido do alimento ou infundido. Ocasionalmente, o uso do sulfato de magnésio, como catártico, pode ser absorvido o bastante para produzir uma intoxicação, particularmente da função renal comprometida.

Sinais e Sintomas - fraqueza muscular, queda da pressão sangüínea, sedação e estado de confusão mental. O ECG mostra aumento do intervalo P-R, alargamento dos complexos QRS e elevação das ondas T. A morte, geralmente, resulta da paralisia dos músculos respiratórios.

Conduta - o tratamento é dirigido no sentido de melhorar a insuficiência renal. O cálcio age como antagonista do magnésio e pode ser empregado por via parenteral para benefício temporário. Pode estar indicado na diálise peritoneal ou extracorpórea.

\subsubsection{Hipomagnesemia}

Etiologia - pode ser encontrado no alcoolismo crônico em associação com "delirium tremens", cirrose, pancreatite, acidose diabética, jejum prolongado, diarréia, má absorção, aspiração gastrintestinal prolongada, diurese exagerada, hiperaldosteronismo primário e hiperparatireoidismo, particularmente depois de paratireoidectomia e quando largas doses de Vitamina $\mathrm{D}$ e cálcio são consumidas.

Sinais e Sintomas - hiperirritabilidade neuromuscular e do SNC com movimentos atetóticos, balismos, tremores amplos ("flapping"), sinal de Babinski, nistagmo, taquicardia e arritmias ventriculares, hipertensão e distúrbios vasomotores. Confusão, desorientação e inquietação podem estar em destaque.

Conduta - infusão parenteral de soluções eletrolíticas, contendo magnésio (10 a $40 \mathrm{mEq} / \mathrm{l} / \mathrm{dia}$, durante o período de maior gravidade, seguindo-se manutenção com $10 \mathrm{mEq} / \mathrm{dia}$ ). O sulfato de magnésio pode também ser dado por via IM (4 a 8 g / 66 a $133 \mathrm{mEq}$, diariamente, divididos em quatro doses; os níveis séricos devem ser monitorizados para prevenir a concentração superior a $5-5,5 \mathrm{mEq} / \mathrm{l})$. 


\section{EQUILÍBRIO ACIDOBÁSICO (EAB) E SEUS DESVIOS}

\subsection{Introdução - Alguns conceitos fisiológicos, fundamentais}

A avaliação acidobásica do sangue é feita na grande maioria dos doentes que são atendidos em UTI, qualquer que seja a patologia de base. A sua avaliação é fundamental, pois, além dos desvios do equilíbrio acidobásico, propriamente dito, pode fornecer dados sobre a função respiratória do doente e sobre as condições de perfusão tecidual.

Os sistemas orgânicos enfrentam dois desafios básicos para a manutenção do EAB. O primeiro é a disposição da cota fixa de ácidos, ingerida na dieta diária. O segundo é o destino dado ao $\mathrm{CO}_{2}$ gerado como produto final do metabolismo. Para manter o pH em limites compatíveis com os processos vitais, o organismo lança mão de uma série de mecanismos bioquímicos, com destaque para o papel desempenhado pelo chamado sistema tampão.

O sistema tampão do organismo pode ser dividido em três grandes componentes: bicarbonato/ácido carbônico, proteína e fosfatos. As substâncias tampões são responsáveis pelo fato de que $\mathrm{pH}$ uma solução se modifica menos do que deveria pela adição ou subtração de íons $\mathrm{H}^{+}$. Com a queda do $\mathrm{pH}$ da solução, estas substâncias aceitam os íons $\mathrm{H}^{+}$para entregá-los novamente, quando aumenta o $\mathrm{pH}$, desta maneira, agem contra as modificações abruptas da reação. Entre os tampões do espaço extracelular, o bicarbonato e as proteínas plasmáticas desempenham um papel relevante, enquanto a hemoglobina e os fosfatos estão em primeiro plano no compartimento intracelular. Graças a estes sistemas de tamponamento, pequenas alterações do EAB manifestam-se por um deslocamento do equilíbrio da reação dos tampões com atenuação de modificações significativas da concentração dos íons $\mathrm{H}^{+}$livres ou do $\mathrm{pH}$. O tampão bicarbonato é o mais importante:

$$
\mathrm{CO}_{2}+\mathrm{H}_{2} \mathrm{O} \longrightarrow \mathrm{H}_{2} \mathrm{CO}_{3} \longrightarrow \mathrm{H}^{+}+\mathrm{HCO}_{3}^{-}
$$

A partir desta reação química, é possível deduzir a Equação de Henderson - Hasselbach, fundamental para o entendimento do equilíbrio acidobásico:

$$
\mathrm{pH}=\mathrm{pK}+\log \frac{\mathrm{HCO}_{3}^{-}}{\mathrm{H}_{2} \mathrm{CO}_{3}^{-}}
$$

$\mathrm{O}$ ácido carbônico pode ser representado pela constante 0.03 pela pressão parcial de $\mathrm{C}_{2}$ do sangue arterial, surgindo, no denominador da equação, um gás que expressa a ventilação.

$$
\mathrm{pH}=\mathrm{pK}+\log \frac{\mathrm{HCO}_{3}{ }^{-}}{0.03 \mathrm{X} \mathrm{PaCO}_{2}}
$$

Assim, é possível concluir que a manutenção do $\mathrm{pH}$ depende, fundamentalmente da função renal (numerador da equação) e da função respiratória (denominador da equação).

$\mathrm{pH}=\frac{\text { Função Renal (componente não respiratório ou metabólico) }}{\text { Função Respiratória (componente respiratório) }}$
O termo "metabólico" é um erro consagrado pelo uso, uma vez que que ambos os componentes da Equação de Henderson - Hasselbach envolvem um processo metabólico. Este erro histórico será preservado, falando-se em distúrbios metabólicos e distúrbios respiratórios do $\mathrm{EAB}$.

Considerando-se estes conceitos, os mecanismos de excreção do $\mathrm{H}^{+}$podem assim ser resumidos: a) a excreção pulmonar do íon $\mathrm{H}^{+}$é indireta; o pulmão só excreta substâncias voláteis, isto é, substâncias que podem ser convertidas em gases;

b) a excreção renal não apresenta esta limitação, sendo coadjuvada pelas bases tampões;

c) a média de excreção de $\mathrm{CO}_{2}$ pelos pulmões pode ser mudada rapidamente, em qualquer direção, por alterações apropriadas da ventilação alveolar, porém a hipoventilação, no sentido de poupar $\mathrm{H}^{+}$não é um mecanismo tão eficiente quanto a hiperventilação que elimina este mesmo íon de maneira eficiente, no início de um quadro acidótico;

d) a função renal pela excreção de $\mathrm{H}^{+}$e eletrólitos influencia o estado acidobásico do LEC, porém um período de horas é necessário para que esta influência seja significante.

Um outro detalhe interessante da fisiologia do EAB são as evidências de que o organismo animal, na sua evolução, adquiriu mecanismos naturais de defesa contra a acidose mais eficientes do que os mecanismos contra a alcalose:

a) características próprias da função renal que elimina o $\mathrm{H}^{+}$e reabsorve o $\mathrm{HCO}_{3}^{-}$;

b) curva da dissociação da $\mathrm{Hb}$ : na acidose, a curva se desvia para a direita, diminuindo a afinidade da $\mathrm{Hb}$ pelo oxigênio e, na alcalose, ela se desvia para a esquerda, aumentando a afinidade; 
c) a hiperventilação com alcalose respiratória, desviando a reação do $\mathrm{CO}_{2}$ com a água para a esquerda, é um mecanismo natural de compensação da acidose metabólica, que pode ocorrer normalmente, por exemplo, no exercício físico. A ocorrência do fenômeno inverso é possível na teoria, mas a depressão respiratória, produzindo uma acidose respiratória para compensar uma alcalose metabólica, só ocorreria com um BE >+40, uma situação praticamente impossível;

d) isto reflete em uma maior dificuldade do tratamento da alcalose metabólica, como se observa na prática diária da terapia intensiva.

Os conceitos de reserva alcalina e "Base Excess" (BE) merecem um pequeno comentário. A reserva alcalina (capacidade de ligação de $\mathrm{CO}_{2}$ ) é a quantidade total de $\mathrm{CO}_{2}$ de uma amostra de plasma, separada anaerobicamente, após equilibrá-la com 40 $\mathrm{mmHg}$ de $\mathrm{pCO}_{2}$ à temperatura ambiente (usa-se de preferência o bicarbonato padrão em $\mathrm{mMol} / \mathrm{l})$ (Escola americana, liderada por Davenport).

$\mathrm{O}$ excesso de bases $(\mathrm{BE}=$ Base Excess $)$ é igual à concentração de bases do sangue em $\mathrm{mEq} / \mathrm{l}$, tituladas por um ácido forte a um $\mathrm{pH}$ de 7,40, com uma pCO2 de $40 \mathrm{mmHg}$ e a uma temperatura de $37^{\circ} \mathrm{C}$ (Escola dinamarquesa, liderada por SigaardAndersen).

Com a crescente simplificação da análise do EAB por aparelhos de alto rendimento, a determinação de parâmetros isolados, como a reserva alcalina, em comparação com um levantamento completo do EAB, passou para um segundo plano. e o EHE.

Existem importantes interrelações entre o EAB

a) Lei da eletroneutralidade - Estabelece que a soma das cargas negativas dos ânions deve ser igual à soma das cargas positivas dos cátions. No plasma, há $154 \mathrm{mEq} / \mathrm{L}$ de cátions e, conseqüentemente, $154 \mathrm{mEq}$ de ânions. Em todas as circunstâncias, o sódio responsabiliza-se pela maior parte dos equivalentes catiônicos. Portanto, o bicarbonato constitui-se no elo entre o EAB e o EHE, já que ele faz parte destas duas entidades. Para que se mantenha a eletroneutralidade, quando ocorre uma queda do bicarbonato, ocorre um aumento do cloreto e vice-versa. Assim, a interação entre prótons e ânions, de um modo cumulativo com os componentes normais do soro, resulta em padrões de eletrólitos que possibilitam a classificação de todas as acidoses metabólicas. Os prótons consomem as reservas de álcali, manifestando sua presença sob a forma de hipobicarbonatemia. Como o álcali perdido é substituído por ânions ácidos (fosfato, acetoacetato, cloreto, etc.), segue-se que qualquer ácido, exceto o $\mathrm{HCl}$, substitui o ânion $\mathrm{HCO}_{3}^{-}$, facilmente medido, por ânions que não são medidos rotineiramente. Por este motivo criou-se o conceito de "diferença de ânions" ("ânion gap", DA), que reflete o balanço entre o cátion rotineiramente medido $(\mathrm{Na}+)$ e os ânions rotineiramente medidos $\left(\mathrm{Cl}^{-}+\mathrm{HCO}_{3}^{-}\right)$.

$$
\mathrm{DA}=(\text { “anion gap” })=\left(\mathrm{Na}^{+}\right)-\left(\mathrm{Cl}^{-}+\mathrm{HCO}_{3}^{-}\right)
$$

Como as acidoses por $\mathrm{HCl}$ efetuam uma troca igual de $\mathrm{HCO}_{3}{ }^{-}$perdido por $\mathrm{Cl}^{-}$retido, sem alterar necessariamente $\mathrm{o} \mathrm{Na}^{+}$sérico, a DA permanece dentro da faixa normal (12 $\pm 2 \mathrm{mEq} / \mathrm{l})$, dessa maneira, definindo uma acidose hiperclorêmica ou com DA normal. Todas as outras formas de acidose aumentam o “anion gap", ao substituir o $\mathrm{HCO}_{3}^{-}$por ânions diversos do $\mathrm{Cl}^{-}$. Uma análise crítica do conceito de "anion gap" demonstra sua pouca utilização na prática diária. Qual seria a sua real utilidade? Diagnóstico diferencial entre tipos de acidoses, permitindo pensar em diagnósticos menos comuns? Como índice prognóstico? Uma utilidade real seria como controle de qualidade de dosagens laboratoriais, já que não existe a situação de "anion gap" aumentado, que ocorre só na condição de erros de dosagem. Como, alguns aparelhos de origem americana mostram a "grande vantagem" de fornecer diretamente o valor do "anion gap", pressente-se até um possível lance comercial. Finalmente, merecem menções os Nomogramas de Gamble para a ilustração e integração entre o EAB e o EHE.

b) Lei da isosmolaridade - Determina que a osmolaridade é a mesma, nos sistemas de líquidos dos organismos, entre os quais a água passa livremente. Seu valor normal é em torno de $285 \mathrm{mOsm} / \mathrm{l}$, e, se o número de partículas dissolvidas aumenta em um compartimento a água mobilizar-se-á em direção a ele até que um novo equilíbrio da osmolaridade seja estabelecido.

c) Lei fisiológica do equilíbrio acidobásico - Afirma que o organismo tende a manter o $\mathrm{pH}$ do sangue em torno de um valor normal. Em relação a esta lei, um fato importante é a interação entre o potássio e o $\mathrm{H}^{+}$em relação ao intra e extracelular. No caso de uma acidose, na tentativa de manter o pH do sangue, o potássio sai da célula com a entrada do $\mathrm{H}^{+}$, ocorrendo o contrário na alcalose, ou seja, saída do $\mathrm{H}^{+}$e entrada do potássio para o compartimento intracelular. 


\subsection{Diagnóstico dos distúrbios do equilíbrio aci- dobásico pela análise gasométrica}

Por tratar-se de um texto apenas com pretensões didáticas, antes da apresentação das causas dos distúrbios do $\mathrm{EAB}$, que seria a seqüência lógica, serão apresentados os princípios diagnósticos. Esta inversão tem se mostrado útil, pois torna fácil a dedução posterior das variadas causas de desequilíbrio acidobásico.

O diagnóstico das alterações do EAB é feito pela análise dos valores obtidos através da gasometria sangüínea. Como em todo exame laboratorial, existem fatores que podem influenciar seus resultados, como veremos a seguir

a) em pacientes conscientes, a punção arterial pode resultar em hiperventilação, pelo temor induzido pelo procedimento;

b) a heparina é ácida e, ao menos teoricamente, pode influenciar os valores do $\mathrm{pH}, \mathrm{pCO}_{2}$ e $\mathrm{pO}_{2}$, em amostras pequenas;

c) a presença de leucocitose e grande número de plaquetas reduzirá o valor do $\mathrm{pO}_{2}$, dando a falsa impressão de hipoxemia. A queda na $\mathrm{pO}_{2}$ é negligenciável, se a amostra é armazenada em gelo e analisada dentro de uma hora. Presumivelmente, o metabolismo, em andamento, dos elementos celulares do sangue pode consumir $\mathrm{O}_{2}$ e reduzir a $\mathrm{pO}_{2}$;

d) o resfriamento aumenta o $\mathrm{pH}$ e a saturação de oxigênio, e diminui a $\mathrm{pO}_{2}$;

e) o halotano aumenta falsamente os valores do $\mathrm{pO}_{2}$, porque o eletrodo para o $\mathrm{pO}_{2}$, no aparelho de gasometria, também responde ao halotano.

Ainda sob o ponto de vista da análise gasométrica, alguns detalhes merecem destaque:

a) a adoção da escola dinamarquesa (SigaardAndersen) é praticamente uma unanimidade internacional;

b) quando se solicita uma gasometria sangüínea, o pH, a $\mathrm{pO}_{2}$ e a $\mathrm{pCO}_{2}$ são obtidos por medida eletrônica direta; os valores do $\mathrm{CO}_{2}$ total, $\mathrm{HCO}_{3}, \mathrm{BE}, \mathrm{SatO}_{2}$ são obtidos por medida indireta, através de leitura no nomograma de Sigaard-Andersen;

c) como os distúrbios envolvem mecanismos renais e respiratórios, o diagnóstico deve ser com base na gasometria do sangue arterial;

d) a amostra venosa não permite a análise da função respiratória e sua colheita está sujeita a erros; para fins científicos, deve, inclusive, ser colhida na artéria pulmonar, onde o sangue venoso é misto; porém, duas informações práticas podem ser obtidas pela análise da gasometria venosa: 1) a $\mathrm{pO}_{2}$ venosa, quando comparada com a pO $\mathrm{p}_{2}$ arterial, dá uma idéia do débito cardíaco (diferença arteriovenosa grande com $\mathrm{pO}_{2}$ venoso baixo significa baixo débito, com os tecidos extraindo muito o oxigênio da hemoglobina pelo fluxo lento, sendo esta uma situação ainda favorável para se tentar a reversão de um estado de choque) e; 2) a diferença arteriovenosa pequena, com progressivo aumento da $\mathrm{pO}_{2}$ venosa, indica um "shunt" sistêmico, ou seja, um agravamento das trocas teciduais); portanto, o principal dado fornecido pela gasometria venosa é a $\mathrm{pO}_{2}$.

Pelo acima exposto, fica claro que o diagnóstico dos distúrbios do EAB deve embasar-se nos valores da gasometria arterial.

Antes da análise das possibilidades diagnósticas da gasometria arterial, é importante que se definam os valores normais de seus parâmetros. Para Ribeirão Preto, Manço \& Terra Filho definiram, por amostragem, os seguintes valores normais (Tabela II):

\begin{tabular}{|c|c|}
\hline $\mathrm{pH}=7,35$ a 7,45 & $\mathrm{CO} 2$ = 23 a $27 \mathrm{mMol} / \mathrm{L}$ \\
\hline $\mathrm{pO} 2=70$ a $90 \mathrm{mmHg}$ & $\mathrm{HCO} 3$ = 22 a $26 \mathrm{mEq} / \mathrm{L}$ \\
\hline $\mathrm{pCO} 2$ = 35 a $45 \mathrm{mmHg}$ & $\mathrm{BE}=-3.5 \mathrm{a}+4,5 \mathrm{mEq} / \mathrm{l}$ \\
\hline
\end{tabular}

*Informação pessoal: Manço \& Terra-Filho

Pela gasometria arterial, é possível o diagnóstico dos desvios do componente respiratório $\left(\mathrm{O}_{2}\right.$ /oxigenação e $\mathrm{pCO}_{2}$ /ventilação) e do componente metabólico $\left(\mathrm{BE} \mathrm{e} \mathrm{HCO}_{3}^{-}\right)$. (Figura 1)

Um nomograma clássico bastante útil é o apresentado por West em seu livro, "Fisiopatologia Pulmonar Moderna" (Figura 2). Este nomograma permite o diagnóstico diferencial de praticamente todos os tipos de insuficiência respiratória, sendo complementar aos dados da Figura 1. Trata-se de um nomograma Ventilação $\left(\mathrm{pCO}_{2}\right)$ / Oxigenação $\left(\mathrm{pO}_{2}\right)$. Como todas as insuficiências respiratórias caracterizam-se pela hipóxia, o diagnóstico diferencial é dado pelo padrão ventilatório, ou seja, pela variação da $\mathrm{pCO}_{2}$.

a) $\mathrm{Na}$ hipoventilação pura, o aumento da $\mathrm{pCO}_{2}$ arterial é extremamente rápido, atingindo valores superiores a $80 \mathrm{mmHg}$ com vasodilatação cerebral e falência cardiorrespiratória. 

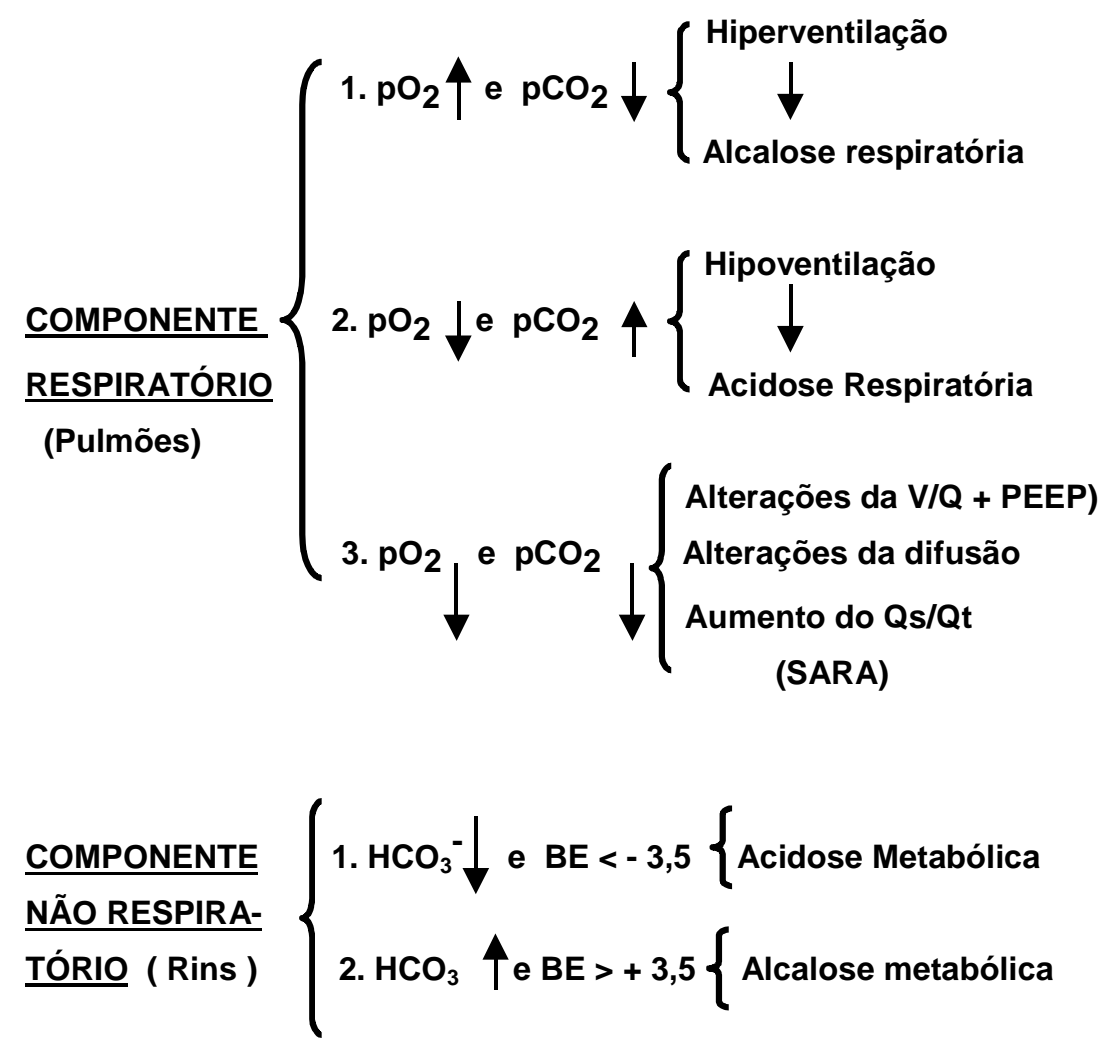

Figura 1 - Interpretação da gasometria arterial.

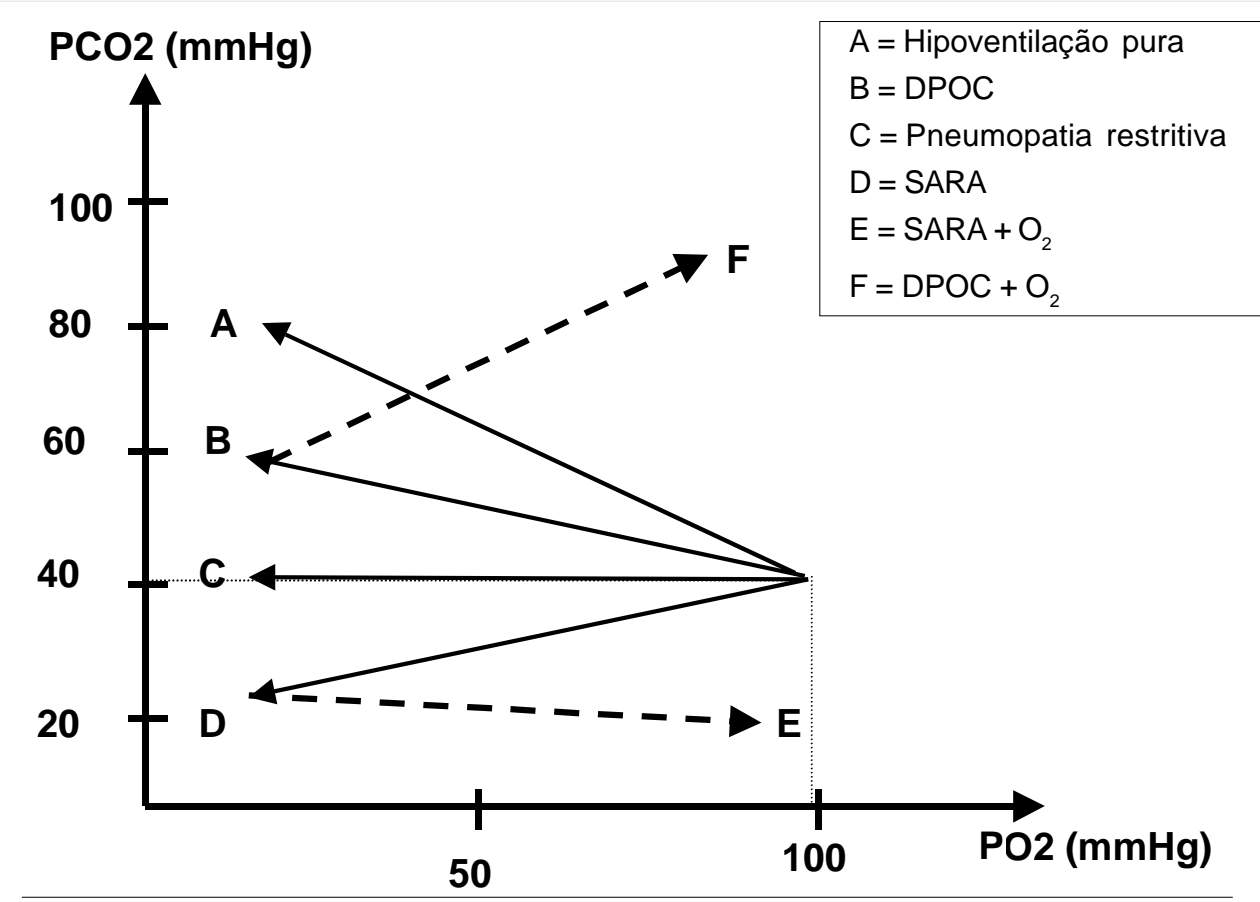

Figura 2 - Nomograma $\mathrm{pCO}_{2} / \mathrm{pO}_{2}$ (West) - Diagnóstico diferencial de todas as modalidades de insuficiência respiratória. 
b) Nos casos de descompensação da doença pulmonar obstrutiva crônica (DPOC), o aumento da $\mathrm{pCO}_{2}$ arterial é mais lento, dificilmente atingindo valores superiores a $77-75 \mathrm{mmHg}$.

c) Nas pneumopatias restritivas, a $\mathrm{pCO}_{2}$ permanece normal, porque existe uma compensação pela característica hiperventilação destas doenças.

d) Na Síndrome da Angústia Respiratória do Adulto (SARA), ocorre uma queda da $\mathrm{pCO}_{2}$ arterial como uma conseqüência do efeito "shunt" (áreas bem perfundidas e mal ventiladas com alta difusibilidade do $\mathrm{CO}_{2}$ ).

E) Com o tratamento adequado da SARA, a oxigenação pode melhorar, porém uma não observância da normalização da $\mathrm{pCO}_{2}$ pode significar que ainda persistem áreas bem perfundidas e mal ventiladas, levando, ainda, ao efeito "shunt".

F) O excesso de oxigênio oferecido a pacientes portadores de DPOC pode levar a uma elevação da $\mathrm{pCO}_{2}$, inclusive atingindo valores superiores a 80 $\mathrm{mmHg}$. Isto se deve ao fato de a ventilação destes pacientes ser controlada por quimiorreceptores aórticos e carotídeos, que respondem à hipóxia e à acidose.

\subsection{Causas mais comuns dos distúrbios do EAB}

De um modo bastante simplificado, as causas mais comuns dos distúrbio do EAB podem ser agrupadas conforme relato abaixo.

\subsubsection{Acidose respiratória}

- Aguda: por comprometimento do SNC (poliomielite anterior e aguda, intoxicações exógenas, comas, traumas); por comprometimento anatômico ou funcional da caixa torácica (ossos e músculos).

- Crônica: por lesões pulmonares (insuficiência respiratória crônica)

\subsubsection{Alcalose respiratória}

- Aguda: estimulação do Centro Respiratório Bulbar (CRB) (encefalites, emoção, febre e infecções sistêmicas, intoxicação por salicilato, hipoxemia); reflexos (choque); por estimulação de receptores torácicos (atelectasia, pneumopatias agudas).

- Crônica: vários mecanismos (assistência ventilatória, insuficiência hepática/amônia, lesões do SNC, infecções, hipoxemia, hipertireoidismo)

\subsubsection{Acidose metabólica}

- Por adição de ácido forte: Aguda exógena (infusão de $\mathrm{NH}_{4} \mathrm{Cl}$ ); Aguda endógena (acidose láctica/ácido láctico, acidose diabética/corpos cetônicos, cetose de jejum, azotemia por IRA/ácido sulfúrico, ácido fosfórico), Crônica: azotemia/IRC.

- Por perda de bicarbonato: Aguda (diarréia); Crônica (fístula pancreática, acidose tubular renal).

\subsubsection{Alcalose metabólica}

- Por perda de ácido forte: Aguda (vômitos), Crônica/perda de potássio (diarréia crônica, corticóides, diuréticos).

- Por ganho de bicarbonato: Aguda exógena (infusão de bicarbonato); Aguda endógena ("stress"); Crônica (ingestão de antiácidos).

Existem situações clínicas importantes que apresentam padrões de alterações do EAB que merecem um breve comentário.

a) Estado de choque - A regra é a ocorrência de acidose metabólica devida à má perfusão tecidual com conseqüente metabolismo celular anaeróbio. Em uma fase inicial, existe a tentativa de compensação respiratória, e, em fase final a regra é uma acidose mista.

b) Parada cardíaca - Ocorre acidose metabólica e respiratória, respectivamente, pela parada brusca de oxigenação tecidual e da ventilação pulmonar. Nestes casos, os pacientes devem ser hiperventilados, pois o tratamento da acidose é feito com o bicarbonato de sódio que é doador de $\mathrm{CO}_{2}$.

c) Circulação extracorpórea (CEC) - Por melhor que seja sua técnica, vários são os mecanismos que elevam a uma inadequada perfusão tecidual (hipofluxo, hipotermia, hiperatividade simpática e ausência de fluxo pulsátil) com conseqüente acidose metabólica. Por outro lado, o uso de oxigênio puro no oxigenador leva, muitas vezes, a uma acentuada diminuição do $\mathrm{CO}_{2}$. A alcalose metabólica pode ocorrer pelo excesso de bicarbonato administrado durante a CEC ou, no pós-operatório, pela perda excessiva de potássio muito comum durante a derivação cardiopulmonar. Um outro problema digno de menção é a ocorrência de alcalose metabólica tardia (48-72 horas no pós-operatório). Pode ocorrer pelo metabolismo do citrato ou do lactato da solução de Ringer-Lactato no perfusato. Existem evidências de que esta alcalose seja mais devida ao citrato do anticoagulante do sangue politransfundido, do que ao uso do Ringer-Lactato.

d) Politransfusão sanguiínea - $O$ sangue estocado possui uma considerável carga de radicais ácidos, 
devida, em grande parte, a um acúmulo de ácidos orgânicos (ácido cítrico do anticoagulante e o ácido láctico gerado pela hipotermia da estocagem e pela hipóxia). Se ocorrer acidose metabólica, deve-se proceder à alcalinização, antes feita rotineiramente $\mathrm{e}$, hoje, conforme as necessidades mostradas por gasometrias seriadas. Além disso, o sangue estocado tem os seus níveis de 2,3 difosfoglicerato (2,3 DPG) diminuídos, o que leva a um deslocamento da curva de dissociação da hemoglobina para a esquerda com aumento da sua afinidade pelo oxigênio, piorando a oxigenação periférica e, conseqüentemente, agravando a acidose metabólica. Pode ocorrer, mais tardiamente, uma alcalose metabólica devida à metabolização do citrato pelo fígado.

e) Alimentação parenteral - No início desta técnica de suporte nutricional a acidose metabólica era uma grave e freqüente complicação, que ocorria porque alguns aminoácidos essenciais - hisitidina, lisina, ornitina e arginina - encontravam-se nas soluções sob a forma de cloridrato. Esta complicação tornou-se mais rara com as soluções de aminoácidos mais recentes que substituem o cloridrato por aspartato.

f) Insuficiência renal crônica - A regra é a existência de acidose metabólica por adição de ácidos fortes (sulfúrico e fosfórico) devido à azotemia. Pode ocorrer ainda acidose metabólica pela subtração do bicarbonato, devida à chamada acidose tubular renal. Este distúrbio é raro, freqüentemente associada a síndromes genéticas, e são de dois tipos: distal devido a uma incapacidade do túbulo distal de manter gradiente máximo de $\mathrm{H}^{+}$entre a luz tubular e o sangue, e proximal devido a uma deficiência de reabsorção do bicarbonato no início do néfron. Os pacientes portadores de insuficiência renal crônica, em geral, adaptam-se à acidose metabólica.

g) Diabetes mellitus - Ocorre acidose metabólica por adição de ácidos devidos aos corpos cetônicos (ácidos acetoacético e betaidroxibutírico). Muitas vezes só o emprego da insulina é o suficiente para o seu tratamento pela diminuição da produção dos corpos cetônicos, sem a necessidade do emprego de bicarbonato.

h) Afecções gastrintestinais - Nelas, as principais alterações podem ser divididas em três grupos: acidose metabólica, alcalose metabólica e perda de potássio. A acidose metabólica pode ocorrer por perda de bicarbonato nas diarréias graves e nas fístulas pancreáticas. A acidose pode ainda ocorrer devido a um estado de choque secundário, por exemplo, a uma trombose mesentérica, pancreatite aguda ou fístula pancreática. A alcalose metabólica pode ocorrer por perda de suco gástrico ou perda de potássio (diarréia, tumores vilosos do reto, tumores do pâncreas, fístulas biliares, uso excessivo de laxativos).

\subsection{Tratamento dos distúrbios do EAB}

\subsubsection{Princípios gerais}

Alguns preceitos devem ser seguidos para um adequado tratamento dos desvios do EAB, lembrando-se sempre que a gasometria é um exame subsidiário que deve ser analisado em conjunto com os dados clínicos do paciente.

a) $\mathrm{O}$ tratamento deve fundamentar-se em dosagens frequientes e seriadas dos gases e do $\mathrm{pH}$ sanguiíneo.

b) Não confiar de forma absoluta em qualquer resultado de laboratório.

c) Não corrigir as alterações muito rapidamente;

d) normalizar, inicialmente, o volume sanguíneo e a perfusão tecidual.

e) Não corrigir o pH, o cálcio e o potássio isoladamente.

\subsubsection{Tratamento da acidose respiratória}

Oxigenação e ventilação adequadas: manutenção das vias aéreas livres, correção da hipóxia e/ou hipercapnia, remoção de secreções e tratamento das infecções respiratórias, quando presentes. Um erro freqüente é a administração de bicarbonato de sódio com base apenas no valor do $\mathrm{pH}$.

\subsubsection{Tratamento da alcalose respiratória}

O objetivo é combater a hiperventilação com sedação de pacientes ansiosos e histéricos. É um distúrbio freqüente em pacientes submetidos a assistência respiratória, principalmente se curarizados. A diminuição da hipoventilação pode ser tentada pelo aumento do espaço morto, diminuição do volume corrente e pela utilização da Ventilação Mandatória Intermitente (IMV), que tem por característica a normalização da $\mathrm{pCO}_{2}$, uma vez que permite a respiração espontânea, intercalada pelo auxílio do respirador.

\subsubsection{Tratamento da Síndrome da Angústia Respiratória Aguda (SARA)}

Não é objetivo deste texto discutir esta entidade em detalhes. A SARA é um problema de "barreira alveolocapilar", causada pela presença de edema pulmonar intersticial. Caracteriza-se por diminuição da capacidade residual funcional, alteração da relação ventilação/perfusão (V/Q) e aumento do "shunt" pulmonar (Qs/Qt). 
Basicamente, seu tratamento consiste em instalar-se assistência respiratória com a associação de Ventilação Mandatória Intermitente (IMV) "Intermitent Mandatory Ventilation" com Pressão Expiratória Positiva Final (PEEP) "Positive End Expiratory Pressure", restrição hídrica, diuréticos, processos dialíticos, metilprednisolona, albumina humana (apenas nas fases iniciais, para aumentar a pressão coloidosmótica e ajudar a diminuir o edema pulmonar intersticial, pois, em fases avançadas, pode extravasar para o alvéolo, contribuindo para a formação de membrana hialina), antibióticos. A utilização do nutroprussiato de sódio, na tentativa de reduzir a hipertensão pulmonar, pode piorar a "shuntagem", se diminuir muito a pressão arterial sistêmica. A recente utilização de óxido nítrico inalado para reduzir a hipertensão pulmonar de modo seletivo é promissora, mas ainda controversa, havendo mais evidências de que não muda a evolução da SARA. Os valores da $\mathrm{pO}_{2}$ e da $\mathrm{pCO}_{2}$ só voltarão à normalidade com a regressão da situação do "shunt" pulmonar aumentado.

\subsubsection{Tratamento da acidose metabólica}

Utiliza-se o bicarbonato de sódio, cuja quantidade necessária para a correção da acidose, em mEq, é fornecido pela Fórmula de Mellengard-Astrup:

\section{$\underline{0,03 \times \text { peso }(\mathrm{Kg}) \times \mathrm{BE}}$}

(2 a 3)

O tratamento da acidose metabólica pode ser feito por estimativa, caso não se disponha dos dados gasométricos, utilizando-se, em média, $2 \mathrm{mEq} / \mathrm{Kg}$ de bicarbonato de sódio como dosagem inicial, seguidos de dosagens criteriosas. Erro comum é o emprego desta solução alcalina em excesso, que pode aumentar muito a osmolaridade do sangue, dificultando as trocas celulares, ou, ainda, induzir arritmias cardíacas pela alcalose metabólica. O bicarbonato de sódio é, universalmente, o elemento utilizado para tratar a acidose metabólica na parada cardíaca. Tem sido estudada a utilização do tampão TRIS (THAM), que teria a vantagem de não ser doador de gás carbônico e não necessitar de hiperventilações, além de sua provável ação superior nas correções das acidoses intracelulares. Como não se observa a utilização rotineira do tampão TRIS, pode-se inferir que, em termos de custo-benefício, não deva haver grandes vantagens sobre o uso do bicarbonato de sódio,

\subsubsection{Tratamento da alcalose metabólica}

Reposição de cloretos, acetazolamida, cloridrato de arginina, $\mathrm{HCl}(0,1 \mathrm{~N}), \mathrm{NH}_{4} \mathrm{Cl}($ ?). Desde os anos setenta, a utilização do cloridrato de arginina foi utilizado no Centro de Terapia Intensiva do Hospital das Clínicas de Ribeirão Preto. A sua administração era empírica (7,5 g/12 horas), uma vez que só a sua fração catabolizada seria acidificante. Conseguiam-se reversões parciais da alcalose metabólica, que se recuperava algumas horas depois. Com o tempo, passou-se a utilizar mais a reposição de cloreto de potássio em associação com a acetazolamida, a qual, inibindo a anidrase carbônica, aumenta a excreção urinária de bicarbonato. A experiência com $\mathrm{HCl}$ foi pequena e nunca se utilizou o $\mathrm{NH}_{4} \mathrm{Cl}$ por ser neurotóxico.

\subsection{Efeitos deletérios dos distúrbios do EAB}

Tanto a acidose como a alcalose apresentam uma série de efeitos indesejáveis, que devem ser de pleno conhecimento, e estão representados nas Tabelas III e IV.

\section{Tabela III - Efeitos deletérios da acidose aguda}

- Sobrecarga respiratória.

- Anorexia, náuseas, vômitos e alterações neurológicas. - Hiperpotassemia.

- Diminuição da responsividade às catecolaminas e depressão da contratilidade miocárdica.

- Vasoconstrição renal e oligúria.

- Resistência à ação da insulina.

Tabela IV - Efeitos deletérios de alcalose aguda

- Hipocalcemia por diminuição do cálcio ionizável.

- Hipopotassemia com aumento da perda urinária de $\mathrm{K}^{+}$.

- Alteração da relação $\mathrm{K}^{+}$intracelular/ $\mathrm{K}^{+}$extracelular no miocárdio, com susceptibilidade a arritmias

- Aumento da afinidade da $\mathrm{Hb}$ pelo $\mathrm{O}_{2}$ (desvio da curva de dissociação para a esquerda), com hipóxia tecidual.

- Acidose paradoxal do líquor, com piora das condições neurológicas.

A alcalose metabólica, cuja importância clínica costuma ser relegada a um plano secundário, merece um lugar de destaque entre os possíveis distúrbios da homeostase do paciente gravemente enfermo e daqueles submetidos a grandes cirurgias. Além de aumentar a afinidade da $\mathrm{Hb}$ pelo $\mathrm{O}_{2}$, tem-se dado importância à alcalose metabólica como causa de arritmia cardíaca, principalmente à supraventricular, que não apresenta boa resposta aos antiarrítmicos convencio- 
nais, admitindo-se, inclusive, a ocorrência de morte súbita e sua correlação com aumento da mortalidade em pacientes graves.

A Figura 3 apresenta um resumo das possibilidades diagnósticas e terapêuticas dos distúrbios do EAB. Este quadro, associado ao Nomograma de West $\left(\mathrm{pCO}_{2} / \mathrm{pO}_{2}\right)$, resume grande parte dos conhecimentos utilizados na prática clínica diária.

\subsection{Exercícios gasométricos}

Apresentam-se, a seguir, exemplos comentados de gasometrias arteriais que mais ocorrem na prática médica. É evidente que a gasometria é um exame complementar que deve ser analisado dentro do quadro clínico apresentado pelo paciente. Esta parte do texto tem apenas a finalidade de ajudar na interpretação prática da gasometria arterial. Os diagnósticos e as condutas serão baseados nas Figuras 1 e 3.

\section{Caso 1}

$\mathrm{pH}=7,30 ; \mathrm{p0}_{2}=86 ; \mathrm{pCO}_{2}=39 ; \mathrm{HCO}_{3}{ }^{-}=18,12 ; \mathrm{BE}=-7,5$.

Diagnóstico: ausência de alterações respiratórias e acidose metabólica leve.
Conduta: acidoses com BE até 7-8 sem sobrecarga respiratória não necessitam de tratamento, ocorrendo compensação pelo próprio organismo. Observar que o valor do $\mathrm{pH}$ está abaixo do normal. No exemplo, não se observam os mecanismos de compensação respiratória, e ele é bastante observado nas acidoses do jejum pré-operatório.

\section{Caso 2}

$\mathrm{pH}=7,42 ; \mathrm{pO}_{2}=99 ; \mathrm{pCO}_{2}=21,39 ; \mathrm{HCO}_{3}^{-}=18,12 ; \mathrm{BE}=-8,0$

Diagnóstico: acidose metabólica compensada por alcalose respiratória.

Conduta: esta é uma resposta natural do organismo, ou seja, a hiperventilação para eliminação indireta $\mathrm{H}^{+}$. Apesar do BE ser semelhante ao do caso 1 , neste caso, deve-se tratar a acidose, pois esta deve ser importante a ponto de desencadear os mecanismos respiratórios de compensação, que, no exemplo apresentado foi, inclusive, capaz de normalizar o $\mathrm{pH}$.

\section{Caso 3}

$\mathrm{pH}=7,61 ; \mathrm{pO}_{2}=91 ; \mathrm{pCO}_{2}=41 ; \mathrm{HCO}_{3}{ }^{-}=39,81 ; \mathrm{BE}=+18$

Diagnóstico: ausência de alterações respiratórias e alcalose metabólica.

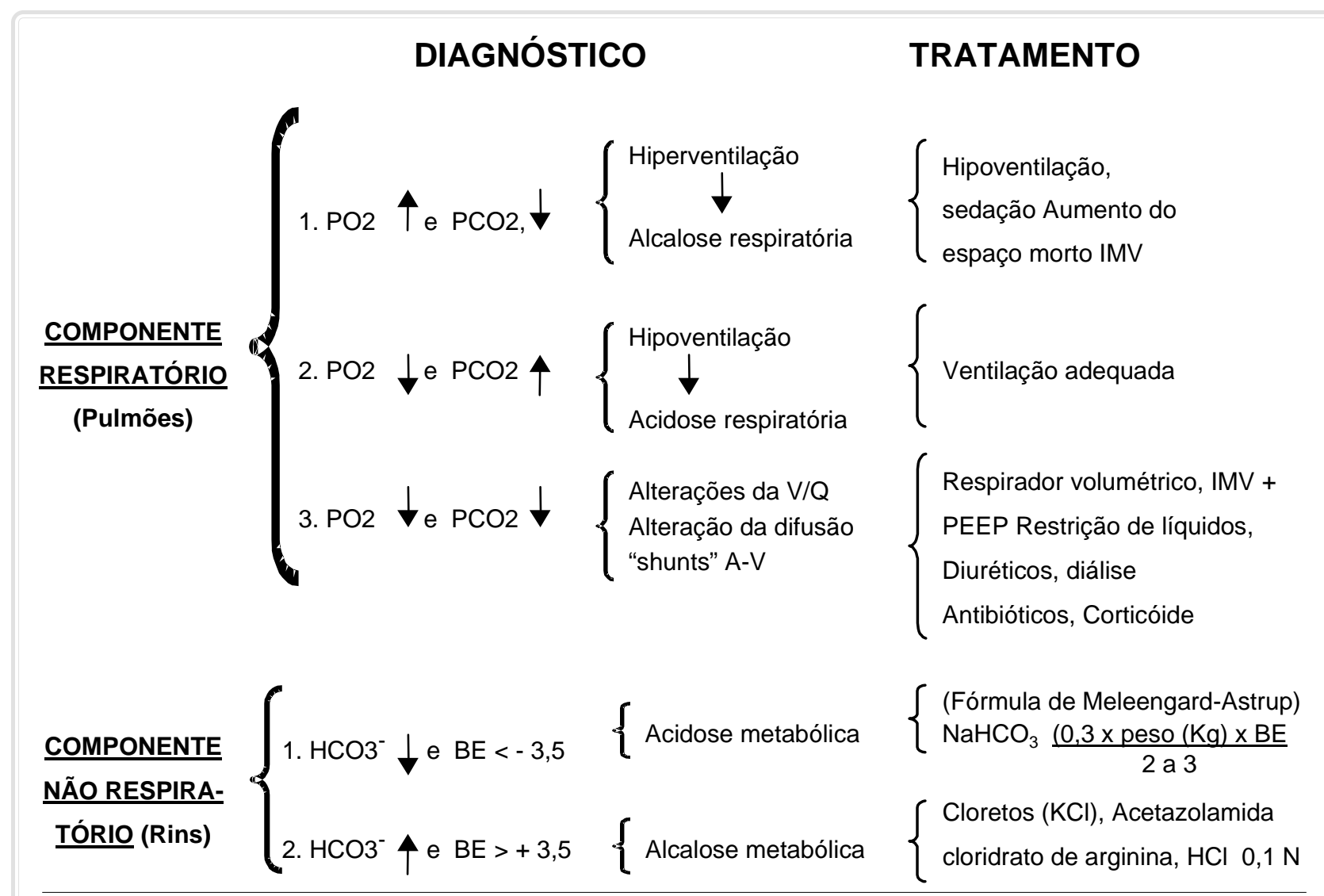

Figura 3 - Resumo das possibilidades diagnósticas e terapêuticas dos distúrbios do equilíbrio acidobásico. 
Conduta: uma boa parte das alcaloses metabólicas estão associadas a hipopotassemia e/ou hipocloremia, portanto, estes íons devem ser dosados no plasma.Caso estejam normais, optar por outro agente acidificante: HCI 0,1 a $0,2 \mathrm{~N}$, cloridrato de arginina. Lembrar que a acetazolamida é de grande utilidade no tratamento das alcaloses de adição e que o cloreto de amônio tem seu uso limitado pela neurotoxidade.

\section{Caso 4}

$$
\mathrm{pH}=7,29 ; \mathrm{pO}_{2}=60 ; \mathrm{pCO}_{2}=57 ; \mathrm{HCO}_{3}^{-}=26,5 ; \mathrm{BE}=-1
$$

Diagnóstico: acidose respiratória sem alterações metabólicas.

Conduta: esta gasometria pode ser perfeitamente aceitável para um paciente portador de doença pulmonar obstrutiva crônica. Caso não se trate de um paciente enfisematoso, deve-se buscar a causa da hipoventilação e tratá-la por meio de uma ventilação adequada.

\section{Caso 5:}

$$
\mathrm{pH}=7,45 ; \mathrm{pO}_{2}=55 ; \mathrm{pCO}_{2}=61 ; \mathrm{HCO}_{3}^{-}=26,5 ; \mathrm{BE}=+19
$$

Diagnóstico: acidose respiratória e alcalose metabólica.

Conduta: devem-se tratar ambos os desvios do equilíbrio acidobásico. Comumente interpreta-se o presente quadro gasométrico como acidose respiratória compensada por alcalose metabólica, o que leva a uma conduta inadequada. Costuma-se tratar os dois distúrbios, pois sabe-se que os mecanismos naturais de defesa contra a acidose são muito mais eficientes do que os mecanismos de defesa contra a alcalose. Por outro lado, se o paciente for um enfisematoso, pode-se interpretar a alcalose metabólica como uma conseqüência da hipercapnia crônica, devendo-se tratá-la com o emprego de acetazolamida.

\section{Caso 6}

$$
\mathrm{pH}=7,63 ; \mathrm{pO}_{2}=100 ; \mathrm{pCO}_{2}=22 ; \mathrm{HCO}_{3}^{-}=22,36 ; \mathrm{BE}=+4,5
$$

Diagnóstico: alcalose respiratória e alcalose metabólica leve.

Conduta: tratar a alcalose respiratória. Este é um distúrbio comum que ocorre com o uso de respiradores mecânicos e, no caso, poder-se-ia diminuir a frequiência respiratória ou aumentar o espaço morto. Uma vez que a $\mathrm{p}_{2}$ se apresenta em níveis normais, talvez não seja conveniente diminuir o volume corrente. Caso se trate de uma hiperventilação psicogênica, deve-se promover à sedação do paciente ou, se possível, fazê-lo respirar em saco fechado.

\section{Caso 7}

$$
\mathrm{pH}=7,30 ; \mathrm{pO}_{2}-55 ; \mathrm{PCO} 2=18 ; \mathrm{HCO}_{3}^{-}=20,2 ; \mathrm{BE}=-4,0
$$

Diagnóstico: sempre que houver hipóxia com hipocapnia deve-se pensar em alterações pulmonares funcionais (alteração da relação ventilação-perfusão, da difusão alveolocapilar, "shunts" arteriovenosos intrapulmonares). Na prática médica, até prova em contrário, trata-se de Insuficiência Respiratória Aguda do Adulto ("pulmão de choque", SARA) devido a edema pulmonar intersticial.

Conduta: procurar tratar a moléstia de base, assistência respiratória com respirador volumétrico e IMV + PEEP, metilprednisolona, furosemide, diálise albumina humana, quando houver hipoproteinemia nas primeiras fase da SARA.

\section{QUESTÕES DIRIGIDAS}

\subsection{Questões dirigidas sobre o equilíbrio hidro- eletrolítico}

1. Descreva sucintamente os compartimentos hídricos orgânicos.

2. Conceitos de permeabilidade, tonicidade, pressão coloidosmótica e pressão osmótica.

3. Indicadores clínicos para a realização do balanço hídrico diário no paciente cirúrgico.

4. Qual a importância das chamadas perdas para o terceiro espaço ?

5. Defina desidratação.

6. Quais as causas mais comuns de desidratação ?

7. Sinais e sintomas da desidratação.

8. Conduta geral na desidratação.

9. Princípios terapêuticos do edema.

10. Definição, diagnóstico e conduta da intoxicação hídrica.

11. Diagnóstico e conduta na hipernatremia.

12. Diagnóstico e conduta na hiponatremia.

13. Diagnóstico e conduta na hiperpotassemia.

14. Diagnóstico e conduta na hipopotassemia.

15. Diagnóstico e conduta na hipercalcemia.

16. Diagnóstico e conduta na hipocalcemia.

17. Diagnóstico e conduta na hipermagnesemia.

18. Diagnóstico e conduta na hipomagnesemia.

\subsection{Questões dirigidas sobre o equilíbrio acido- básico}

1. Quais os dois desafios básicos que os sistemas orgânicos enfrentam para a manutenção do EAB?

2. Deduza a Equação de Henderson-Hasselbalch e discuta a sua importância. 
3. Quais as características das respostas pulmonares e renais na eliminação do $\mathrm{H}^{+}$?

4. Quais as principais evidências de que o organismo animal possui mecanismos naturais de defesa contra a acidose mais eficientes do que os mecanismos contra a alcalose ?

5. Como pode ser dividido o sistema-tampão do organismo.

6. Qual o conceito de reserva alcalina ?

7. Qual o conceito de "Base Excess" ?

8. Qual o conceito de "Anion gap" e qual a sua importância?

9. Quais os principais diagnósticos dos distúrbios do EAB com base na gasometria arterial ?

10. Represente e descreva o nomograma $\mathrm{pO}_{2} / \mathrm{pCO}_{2}$ (West). Qual a sua importância prática ?

11. Qual a importância da amostra venosa ?

12. Cite os principais fatores que podem, potencial- mente, alterarem os valores da gasometria ?

13. Cite quais as principais causas da acidose respiratória.

14. Cite as principais causas da alcalose respiratória.

15. Cite as principais causas da acidose metabólica.

16. Cite as principais causas da alcalose metabólica.

17. Quais as possibilidades terapêuticas para o tratamento da acidose respiratória?

18. Quais as possibilidades terapêuticas para o tratamento da alcalose respiratória?

19. Quais as possibilidades terapêuticas para o tratamento da SARA ?

20. Quais as possibilidades terapêuticas para o tratamento da acidose metabólica ?

21. Quais as possibilidades terapêuticas para o tratamento da alcalose metabólica ?

22. Quais os principais efeitos deletérios da acidose?

23. Quais os principais efeitos deletérios da alcalose?

EVORA PRB; REIS CL; FEREZ MA; CONTE DA \& GARCIA LV. Fluid, electrolyte and acid-base disorders. A practical review. Medicina, Ribeirão Preto, 32: 451-469, oct./dec. 1999.

ABSTRACT: Fluid, electrolyte and acid-base disorders are very important subjects for all medical specialties. But their practical learning is, sometimes, very difficult.

This text intends to discuss this subject based on more than 20 years of didatic experience teaching medical students, medical residents and post-doctoral students. The text has only didatic pretensions without any academic purpose.

UNITERMS: Fluid. Water. Electrolytes. Acidosis. Alkalosis. Acid-base Equilibrium. WaterEletrolyte Balance.

\section{BIBLIOGRAFIA CONSULTADA}

1 - AMERICAN COLLEGE OF SURGEONS. Assistência cirúrgica intensiva: Comitê de cuidados pré e pós-operatórios. Interamericana, Rio de Janeiro, 1979.

2 - EVORA PRB. Tópicos em terapia intensiva. Associação dos Médicos Residentes de Ribeirão Preto e Centro Acadêmico Rocha Lima da Faculdade de Medicina de Ribeirão Preto USP, Ribeirão Preto, 1978.

3 - EVORA PRB; REIS CL; RIBEIRO PJF; BRASIL JCF; OTAVIANO AG \& SILVA JRP. Alcalose metabólica. tratamento com solução da aminoácidos contendo cloridrato de arginina. Rev Paul Med 97: 25-28, 1981.

4 - EVORAPRB; RIBEIRO PJF; BRASILJCF; SILVAJRP; OTAVIANO AG \& REIS CL. Alcalose metabólica hipoclorêmica. Tratamento pela reposição do cloro por via retal. J Pediatr 50: 253-254, 1981
5 - EVORA PRB. Aspectos práticos sobre o equilíbrio ácidobásico do sangue. Rev Bras Anestesiol 32:123-128,1982.

6 - EVORA PRB. Treatment of the hypocloremic metabolic alkalosis by rectal infusion of chloride. (Letter). Crit Care Med 13: 874, 1985.

7 - EVORA PRB; BONGIOVANI HL; RIBEIRO PJF; BRASIL JCF; OTAVIANO AG \& BOMBONATO R. Alcalose metabólica no posoperatório de cirurgia cardíaca com circulação extracorpórea: Importância do emprego de solução de Ringer-Lactato e do sangue citratado. Rev Paul Med 103: 88-91, 1985.

8 - EVORA PRB. Equilíbrio acidobásico. Klinikos 2: 26-40, 1986.

9 - FAINTUCH J; BIROLINI D \& MACHADO AC. Equilíbrio ácido-básico na prática clínica. Manole, São Paulo, 1975.

10 - MAXWELL MH \& KLEEMAN CR. Clínica das alterações eletrolíticas. $3^{\mathrm{a}}$ ed. Guanabara-Koogan, Rio de Janeiro, 1981. 
11 - MOORE ME. Manual de emergências médicas. Manole, São Paulo, 1976.

12 - NAKAO RM; FREITAS JNA; PORTO ALEGRE EM; SILVA JF \& EVORA PRB. Aspectos práticos sobre os eletrólitos e coração. Rev Soc Cardiol, Ribeirão Preto, 5 (1/4): 9-16, 1981.

13 - PARSONS PE \& WIENER-KRONISH JP. Critical care secrets. Hanley \& Belfus, Philadelphia. 1992.

14 - ROOTH G. Introdução ao equilíbrio ácido-básico e eletrolítico, Atheneu, Rio de Janeiro, 1978.

15 - SCHUMER W \& NIHUS LM. Tratamento do choque. Manole, São Paulo, 1976.

16 - TIERNEY LM; MC PHEE SJ; PAPADAKIS MA \& SCHROEDER AS. Current diagnosis \& therapeutics. Appleton \& Lange, New York, 1993.
17 - TRUNIGER B. Equilíbrio hidro-eletrolítico. Diagnóstico e Terapêutica. E.P.U, São Paulo, 1974

18 - TULLER MA. Acid-base homeostasis and its disorders. Medical Examination Publishing Company, Flushing, NY, 1971.

19 - WEST JB. Fisiopatologia pulmonar moderna. Manole, São Paulo, 1979.

20 - POTTER PA \& PERRY AG. Grande tratado de enfermagem prática. Clínica e prática hospitalar. São Paulo, Livraria Santos Editora, 1996.

Recebido para publicação em 07/04/99

Aprovado para publicação em 05/11/99 